JASEM ISSN 1119-8362 Full-text Available Online at

All rights reserved https://www.ajol.info/index.php/jasem

http://ww.bioline.org.br/ja
J. Appl. Sci. Environ. Manage.

Vol. 22 (8) 1263 -1268 August 2018

\title{
Achieving Groundwater Resource Sustainability at Watershed Scale by Conjunctive Use of Groundwater and surface Resources
}

\author{
*RASI NEZAMI, S; FEIZI, A \\ Department of Civil Engineering, Faculty of Engineering, University of Mohaghegh Ardabili, Ardabil, Iran \\ *Corresponding Email: rasinezami@uma.ac.ir
}

\begin{abstract}
The main goal of paper is to identify optimal water resources management strategies for groundwater resources sustainability achievement in Maharlou-Bakhtegan watershed in Iran and maximum water supply probability to the demand sites. In the present study, conjunctive use of groundwater and surface resources along with a scenario-based analysis approach is examined to achieve the optimal water resource management and plan Maharlou-Bakhtegan watershed using MODSIM model as a decision support system (DSS) for the basic river catchment management. The proposed approach is used to assess the effects of the different management strategies, climate changes, groundwater withdrawal levels and irrigation efficiency on the groundwater resources sustainability, agricultural water supply, and environmental water demand satisfaction. To quantify the system performance, six management scenarios are defined and modelled by MODSIM. For assessment of the system performance in each scenario, three performance indicators including reliability, vulnerability, and resiliency are introduced and defined. The findings showed that the fifth scenario (SC5) strategies satisfied all of the considered management goals and proposed the optimal management solutions for sustainability achievement of the groundwater resources.
\end{abstract}

\section{DOI: https://dx.doi.org/10.4314/jasem.v22i8.19}

Copyright: Copyright (C) 2018 Rasi and Feizi. This is an open access article distributed under the Creative Commons Attribution License (CCL), which permits unrestricted use, distribution, and reproduction in any medium, provided the original work is properly cited.

Dates: Received: 24 June 2018; Revised: 19 July: 2018; Accepted: 22 August 2018

Keywords: Maharlou-Bakhtegan Watershed, Groundwater Resources Sustainability, MODSIM, Scenario Analysis, Performance Indices

As irrigation is the dominant water user in many arid and semi-arid river catchments, agricultural activities account for the majority of water withdrawals from groundwater and surface recourses (Abrishamchi et al., 2007). The decision-making problems regarding water resources such as water allocation, water resources development, conservation and sustainability of fragile ecosystems can be confusing and DSS tool may be helpful (Mugatsia, 2010). Sprague and Carlson (1982) defined a decision support system (DSS) as an interactive computer-based support system facilitating unstructured problems solving for decision makers using data and modelling. Zaman et al., (2009) developed a DSS for integrated water resources management in Bangladesh to assist policy makers and planners by providing information about probable impacts of water-related projects. River basin management DSS is planned to help stakeholders to develop a common image of management and planning goals while obtaining a better understanding of the coordinated operations requirement in complex river basin systems which probably affects multiple jurisdictional entities. They make it possible to assess the hydrologic, economic, environmental, and institutional/legal effects associated with management scenarios and alternative development (Labadie, 2005). One optimization approach for water resources management problems is to model water resources as a problem of dynamic multi-period network flow, in which no uncertainty level is considered and all data are fixed (Labadie, 2005; Ashraf Vaghefi, 2017). Obviously, stochastic optimization methods cannot be utilized when no sufficient statistical information exits regarding the data estimation to support the model especially in cases that the probabilistic rules are not available. In these circumstances, the scenario analysis method could be an alternative approach (Shourian et al., 2008; Rockafellar, 1991). MODSIM is a DSS for the generic river basin management, which is originally conceived in 1978 at Colorado State University (Shourian et al., 2008), making it the longest incessantly preserved river basin management software package that is presently available. An effectively practical method is to model the problem by an optimization network flow model which is supported by a multi-period dynamic graph where no level of uncertainty is considered and all the data are fixed (Kuczkera, 1993; Ashraf Vaghefi, 2017). According to Ahuja et al., (1993) network flow models 
make adopting highly efficient computational algorithms possible even when numerous variables and constraints are required. MODSIM involves modelling abilities for conjunctive use of surface water, groundwater and stream-aquifer interactions simulation (Labadie, 2005). The authors discovered the probability of maintaining network flow structure by assuming non-network constraints in the model, in the water resources management problems, Dai and Labadie (2001) used MODSIM to simulate river catchment network considering water quality issues and constrains. They combined MODSIM and Qual2E models to simulate the irrigation runoffs, which is responsible for river-water quality degradation as well as conflict resolution between various users considering water right priorities. Leu (2001) applied MODSIM to the San Joaquin River Catchment to study the effects of economic policies such as increasing water prices, environmental flows variations in San Joaquin River, and changes in reservoir operations to optimize the present water management strategies. Miller et al., (2005) described the use of MODSIM in analyzing the water transfer covenant between the Imperial Irrigation District (IID) and the San Diego Water County Water Authority in Southern California in the USA. Shourian et al., (2008) developed water resource management strategies using simulation-optimization approach by a combination of MODSIM as a water allocation modelling and particle swarm optimization (PSO) as a search-based optimization model to achieve optimized water resources management strategies in watershed scale.

Berhe et al., (2013) used MODSIM as a DSS of a river basin to model water allocation in Awash River Basin located in Ethiopia. Simulation is conducted based on four scenarios. The outputs of MODSIM model revealed that the incremental release from Koka Dam would exist. Safavi and Enteshari (2016) used a simulation/optimization model based on artificial neural networks (ANN) and an ant system optimization (AS) to solve the monthly conjunctive source of irrigation water in Najafabad Plain located in west-central Iran. They concluded that the simulation model can predict the studied aquifer behavior and it may be utilized as a decision support system. Nabinejad et al., (2017) simulated the hydropower multi-reservoir system operations by MODSIM model with control on the reliability of the system energy yield. In this paper, scenario analysis approach will be evaluated using MODSIM as a generic river catchment management DSS to derive the best water resources management strategies in the Maharlou-Bakhtegan watershed in the south of Iran.

\section{MATERIALS AND METHODS}

Case study and data: The Maharlou-Bakhtegan catchment, mainly drained by the Kor River, is placed in southern Iran (See Fig. 1). The catchment area is $32271 \mathrm{~km}^{2}$ and placed between longitudes $51^{\circ} 45^{\prime}$ and $54^{\circ} 30^{\prime} \mathrm{E}$, latitude $29^{\circ} 35^{\prime}$ and $31^{\circ} 15^{\prime} \mathrm{N}$. Nearby, 16,113 $\mathrm{km}^{2}$ of the objected catchment is covered by mountainous area and $16,158 \mathrm{~km}^{2}$ of is by plain area. The main area of this watershed is located between Doroudzan Dam and Bakhtegan Lake. Currently, the city of Shiraz with the population of $1,227,331$ is the largest urban centre and the most important centre of population and development in the catchment and of course in the south of Iran. Moreover, MaharlouBakhtegan watershed is considered actually important in terms of economical and industrial point of view.

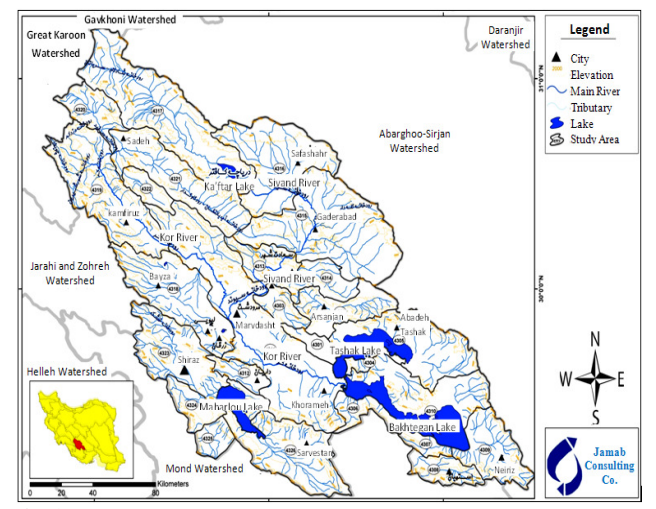

Fig.1. Schematic view of the Maharlou-Bakhtegan catchment

The main objective of the present research is to develop a conceptual framework for obtaining the best management strategies to improve the sustainability of groundwater resources of Maharlou- Bakhtegan catchment. In this regard, hydrometric and climatologic data were collected and used to model the catchment under different scenarios in MODSIM.

Methodology: In the present study, water resources system of the Maharlou-Bakhtegan catchment was modelled in MODSIM. This model was executed by monthly data sets of all water demands and water resources including reservoirs and groundwater resources. The output of the model was calibrated with data sets of the various water consumptions and allocations in the year 2006. In the second step, scenario analysis approach is used to investigate the effects of the conjunctive use of groundwater and surface resources, in supplying the different water demands, on the sustainability of the groundwater resources until planning horizon of 2041. Then, some scenarios are defined based on the probable water resources management strategies. In order to 
investigate the water resources system performance under different water and soil resources management scenarios, system performance indicators including reliability, vulnerability and resiliency indices are calculated.

Scenario analysis and approach: The main purpose of this work is to assess the effects of management actions on supplying the increasing water demands at agricultural areas, environmental needs and their effects on groundwater resources. The efficient management actions include increasing in irrigation efficiency and limited development in the agricultural area during the specified time horizon. In this section, all groundwater resources and water demands supply are modelled by MODSIM in 2006. For the future, five other scenarios are defined involving a different combination of development and management of the soil and water resources at the time horizon of 2041. These scenarios are presented in Table 1. Based on Abbaspour et al., (2009), the impacts of climate change on the runoff regime are considered as $13 \%$ decrease in the whole catchment run-off.

Table 1 Management scenarios and their assumptions

\begin{tabular}{|c|c|c|}
\hline Scenario No. & Scenario Description & Definition and Assumptions \\
\hline $\mathrm{SC} 0$ & $\begin{array}{l}\text { Present condition in } 2006 \text { as the } \\
\text { reference scenario }\end{array}$ & $\begin{array}{l}\text { As reference scenario. Water demands and water } \\
\text { resources condition are based on } 2006 \text {. }\end{array}$ \\
\hline $\mathrm{SC} 1$ & $\begin{array}{l}\text { Water demands increases until } 2041 \\
\text { according to the defined trend }\end{array}$ & $\begin{array}{l}\text { Increased agricultural water demands according } \\
\text { to the growing trend in cultivation area until } 2041\end{array}$ \\
\hline $\mathrm{SC} 2$ & $\begin{array}{l}\text { Water demands increases until } 2041 \\
\text { considering the increase in irrigation } \\
\text { efficiency }\end{array}$ & $\begin{array}{l}\text { Decreased agricultural water consumptions with } \\
\text { respect to } 60 \% \text { improvement of the irrigation } \\
\text { efficiency }\end{array}$ \\
\hline SC3 & $\begin{array}{l}\text { Water demands increases until } 2041 \\
\text { according to the defined trend } \\
\text { considering climate change }\end{array}$ & $\begin{array}{l}\text { Decreased the basin runoffs by } 13 \% \text { and } \\
\text { Increased agricultural water demands according } \\
\text { to the growing trend in cultivation area }\end{array}$ \\
\hline $\mathrm{SC} 4$ & $\begin{array}{l}\text { Water demands increases until } 2041 \\
\text { considering an increase in irrigation } \\
\text { efficiency and climate change }\end{array}$ & $\begin{array}{l}\text { Decreased the basin runoffs by } 13 \% \text { and the } \\
\text { agricultural water consumptions concerning } 60 \% \\
\text { improvement in the irrigation efficiency }\end{array}$ \\
\hline SC5 & $\begin{array}{l}\text { Water demands increases until } 2041 \\
\text { considering an increase in irrigation } \\
\text { efficiency, climate change and } \\
\text { limited the agricultural area } \\
\text { development }\end{array}$ & $\begin{array}{l}\text { Decreased basin runoffs by } 13 \% \text {, decreased } \\
\text { agricultural water consumptions concerning } 60 \% \\
\text { improvement in the irrigation efficiency, } \\
\text { limiting the cultivation area }\end{array}$ \\
\hline
\end{tabular}

Investigation of system performance: The performance indicators are utilized to investigate the findings of the optimization models. These indicators indicate how often the system fails (reliability), how significant the consequences of failure are (vulnerability), and how quickly the system returns to a satisfactory state once a failure occurs (resiliency). The proper definition of performance indicators is related to the main issues and purposes of the water resources planning and management. Based on the description of these indices, the operational position of water resources systems can be categorized as satisfactory (in this case, supplying water demand) and unsatisfactory or failure (deficiency in supplying water demand). The system status in time period $t$ is given by the stochastic variable $X_{t}$. It is a member of $S$ set if it is related to the set of satisfactory outputs; then, it is involved in F set which is the set of all unsatisfactory results (Report of Jamab Consulting Engineers Company, 2011; Karamouz, 2009). In this case, if the allocated water is equal to or greater than water demand, no failure happens, if not, the failure occurs. Reliability is considered as the probability of occurring no failure within a specified period. Based on the above explanation, the reliability of the present study is a measure of system performance in supplying water demand and it is estimated as the following:

$\alpha=\frac{\sum_{i=1}^{T} \theta_{i}}{T} \quad\left\{\begin{array}{c}\theta_{i}=1 \quad \text { if }\left(R_{y, m} \geq D_{y, m}\right) \\ \theta_{i}=0 \quad \text { otherwise }\end{array}\right.$

Where $\alpha$ (reliability) is described as the number of months with supplying water demand out of total months (T) in the planned horizon, $R_{y, m}$ is the amount of water supply in month m of year $y, D_{y, m}$ is the water demand in month $\mathrm{m}$ of year $y$, and $\theta_{i}$ is a binary variable showing the status of supplying water demand. Resiliency defines how quickly a system is improved from failure when occurring the failure. It is essentially a measure of satisfactory circumstance duration and is defined as the following:

$$
\beta=\frac{\sum_{i=1}^{T} \eta_{i}}{T-\sum_{i=1}^{T} \lambda_{i}} \quad\left\{\begin{array}{cc}
\eta_{i}=1 & \text { if }\left(\lambda_{i-1}=0 \text { and } \lambda_{i}=1\right) 2 \\
\eta_{i}=0 & \text { otherwise }
\end{array}\right.
$$


Where $\beta$ (resiliency) is the ratio of the sum of the failure months $\eta_{i}$ to satisfactory status out of total months $\mathrm{T}$ and $\lambda_{i}$ is the binary variable showing the status of supplying a specific water demand simultaneously after the system experienced a failure in that water demand-supply.

Vulnerability calculates the failure magnitude. In water demand-supply systems, the vulnerability can be expressed as the total failure volume during the planning prospect. This indicator is formulated as the following:

$$
\gamma=\sum_{i=1}^{T} V_{i} \quad\left\{\begin{array}{l}
V_{i}=0 \text { if }\left(R_{y, m} \geq D_{y, m}\right) \\
V_{i}=\left(R_{y, m}-D_{y, m}\right) \text { otherwise }
\end{array}\right.
$$

Where $\gamma$ is the resiliency of system and $V_{i}$ is the distance between the present system state and the optimal one.

\section{RESULTS AND DISCUSSION}

In this study, with respect to increase or decrease in the groundwater aquifers water balance, the sustainability of groundwater resources was investigated. According to Figs. 2 and 4, in the first scenario (SC1), 60\% of the agricultural water demands and $80 \%$ of the environmental water needs are supplied in a time horizon of 2041. Fig.4 shows that negative water balance of the groundwater resources has been increased to $347 \mathrm{MCM}$ compared to the reference scenario ( $\mathrm{SC} 0$ ). In the $\mathrm{SC} 1$ scenario, it is suggested that the agricultural water demands supply increase with respect to the pre-defined agricultural area development regarding Iran's immense plan of development without applying any water and soil management policies. It can be easily understood that in the absence of management actions' improvement, agricultural water demand-supply decreases by $25 \%$ in the time horizon of 2041 compared to 2006. By applying the $60 \%$ improvement of the irrigation efficiency in the second scenario (SC2) and assuming the conditions of the previous scenario, 17 and $10 \%$ improvement in agricultural and environmental water demands will be achievable rather than the first scenario, respectively. An advance of $87 \mathrm{MCM}$ occurred in abrogating water balance of groundwater resources in SC2 scenario. The effects of climate change on the rainfall are also considered in the third scenario (SC3). In contrast with the SC2 results, this phenomenon decreases the total catchment runoffs by about $13 \%$ and decreases the agricultural and environmental water needs by 15 and $18 \%$, respectively. Accordingly, in the SC4 scenario, despite increasing the irrigation efficiency up to $60 \%$ and the consequent decrease in agricultural water demands, agricultural water supply is reduced by $1 \%$ due to the effects of climate change. Nevertheless, the environmental water supply in this scenario remained equal to that of scenario (SC1). By limiting the cultivation area development equal to the base SC0 scenario as well as the decrease in the existing water demands supply and allocation trend condition via the fifth scenarios (SC5), despite the considering of the negative effects of the climate change, an improvement is achieved in the agricultural and environmental water demands supply and the negative water balance of the groundwater resources is reduced significantly.

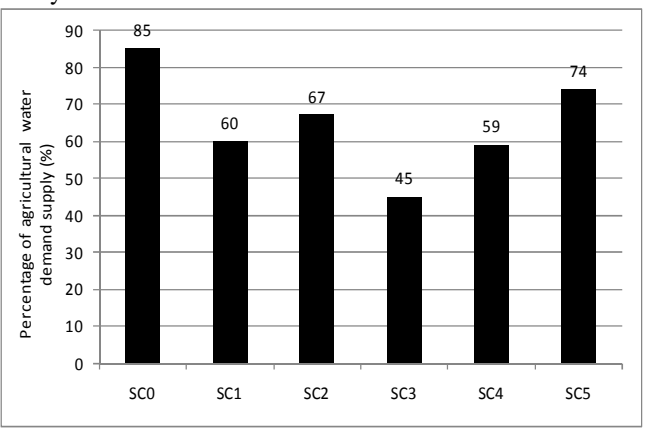

Fig.2. Agricultural water demand-supply level in different scenarios

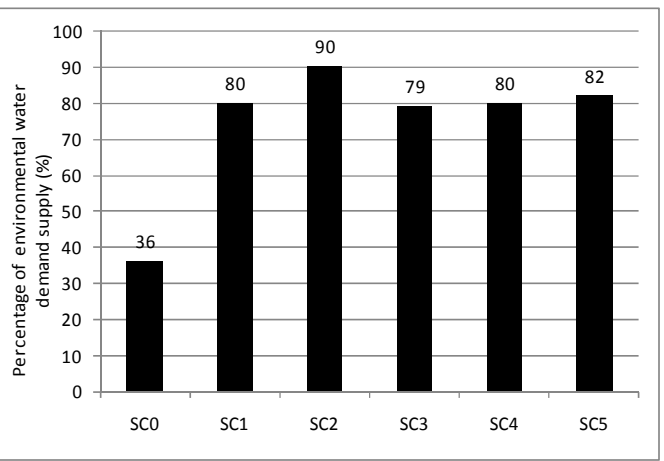

Fig.3. Environmental water demand-supply level in different scenarios

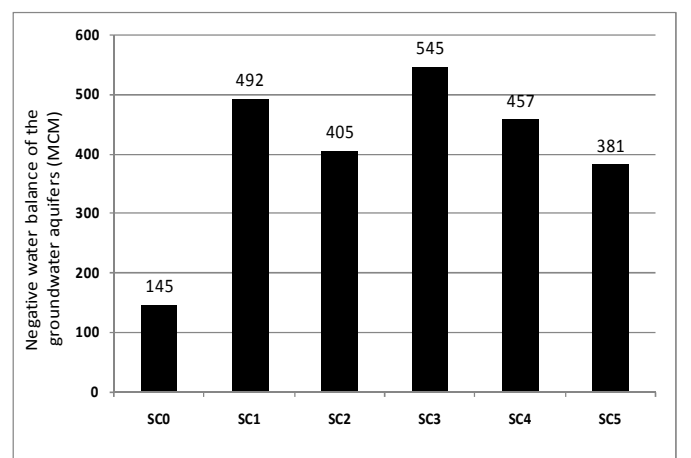

Fig.4. Negative water balance of the groundwater aquifers in different scenarios 
The performance indices of the water resources system of the Maharlou-Bakhtegan catchment for agricultural water supply of the system in five scenarios are presented in Table 2. These indices are calculated for irrigation and drainage networks of the downstream of Sivand, Doroodzan and Mollasadra Dams. According to the table 2, the best results in performance indices of the system are achieved by increasing in irrigation efficiency in SC2 scenario compared to SC1. By applying negative effects of the climate change in SC3 scenario, performance indices of the system decreased considerably which is in contrast to SC2 and SC1 results. Comparison between the results of the fifth SC5 scenario, with and SC4 scenarios suggests that performance indices of the system increase in the agricultural demands.

Table 2 Results of the performance indices evaluation for different scenarios

\begin{tabular}{llll}
\hline $\begin{array}{l}\text { Scenario } \\
\text { Name }\end{array}$ & $\begin{array}{l}\text { Reliability } \\
(\boldsymbol{\%})\end{array}$ & $\begin{array}{l}\text { Resiliency } \\
(\boldsymbol{\%})\end{array}$ & $\begin{array}{l}\text { Vulnerability } \\
\text { (MCM) }\end{array}$ \\
\hline SC1 & 60 & 12 & 11.1 \\
SC2 & 67 & 9.5 & 8.8 \\
SC3 & 45 & 10.6 & 16.5 \\
SC4 & 59 & 9.2 & 9.5 \\
SC5 & 74 & 15 & 8.0 \\
\hline
\end{tabular}

Conclusion: The results revealed that the supposed management actions in SC5, despite the negative effects of climate change in decreasing of the water resources, led to more water demand-supply than the demand sites and improved the system performance indices as well as a considerable increase in the groundwater resources sustainability. The proposed methodology in this research can be applied as a useful means by the water sector managers of the MaharlouBakhtegan catchment for optimal water allocation management considering the sustainability of the limited groundwater resources. It is noteworthy that while one of the major driving forces in the catchment is agricultural development as the largest and the most important supplier of the food security in Iran in the past, current and surely in the future decades, limiting the agricultural area may not be a practical solution for optimal water resources management in the studied catchment. Accordingly, along with limiting the agricultural area development as less as possible, the following solutions are suggested to fulfil the major groundwater resources sustainability as well as integrity goals of the water resources management in Maharlou-Bakhtegan catchment: Increasing the irrigation efficiencies as much as possible in the whole catchment by utilizing effective and modern technologies; Changing cropping patterns to have higher crop yields and lower levels of water demand;
Improving food and water consumption patterns in the society; Accordingly, the examination and evaluation of the individual and combined effects of these alternative solutions can be future fields of studies.

\section{REFERENCES}

Abbaspour, KC; Faramarzi, M; Seyed Ghasemi, S; Yang, H (2009). Assessing the impact of climate change on water resources in Iran. Journal of Water Resources Research, 45: 1-16.

Abrishamchi, A; Alizadeh, H; Tajrishi, M (2007). Water Resources Management Scenario Analysis in the Karkheh River Basin, Iran, Using the WEAP Model. Proceedings of the 2007 American Institute of Hydrology Annual Meeling and Internaltonal Conference Integrate Walershed Management: Partnerships in Science, Technology and Planning. 23(1-4): 1-11.

Ahuja, RK; Magnanti, TL; Orlin, JB (1993). Network Flows: Theory, Algorithms and Applications. Prentice Hall, Englewood Cliff, N.J., pp.864.

Ashraf Vaghefi, S; Abbaspour, K; Faramarzi, M; Srinivasan, R; Arnold, J (2017). Modeling Crop Water Productivity Using a Coupled SWATMODSIM Model. Water, 9(3), 157.

Berhe, FT; Melesse, A M; Hailu, D; Sileshi, Y (2013). MODSIM-based water allocation modeling of Awash River Basin, Ethiopia. CATENA, 109: 118-128.

Dai, T; Labadie, JW (2001). River Basin Network Model for Integrated Water Quantity/Quality Management. J. Water Res. Planning and Manage. 127(5): 295-305.

Dembo, R (1991). Scenario Optimization. Annals of Operations Research, 30 (1): 63-80.

Karamouz, M; Ahmadi, A; Moridi, A (2009). Probabilistic reservoir operation using Bayesian stochastic model and support vector machine. Advances in Water Resources, 32(11): 15881600.

Kuczkera, G (1993). Network Linear Programming Codes for Water Supply Head-Works Modeling. Journal of Water Resources Planning and Management ,119(3): 412-417.

Labadie, J; Larson, R (2006). MODSIM: River basin management decision support system, User 
Manual, Department of Civil Engineering, Colorado State University, Ft. Collins, CO.

Leu, M (2001). Economics-driven simulation of the Friant Division of the Central Valley Project. California, M.S. Thesis, Dept. of Civil Engineering, Univ. of California, Davis, CA.

Miller, DW; Eckhardt, JR; Keller, AA (2005). The Imperial Irrigation Decision Support System Evolution from Project Planning to Operations. Impacts of Global Climate Change. doi:10.1061/40792(173)537.

Mugatsia, EA (2010). Simulation and Scenario Analysis of Water Resources Management in Perkerra Catchment Using WEAP Model. Master of Science Thesis, Grad Eng. B. Tech (Hons) Moi University, pp.156.

Nabinejad, S; Mousavi, SJ; Kim, JH (2017). Sustainable Basin-Scale Water Allocation with Hydrologic State-Dependent Multi-Reservoir Operation Rules. Journal of Water Resources Management, 31(11):3507-3526.

Rockafellar, RT; Wets, RJB (1991). Scenarios and Policy Aggregation in Optimization Under Uncertainty. Mathematics of Operations Research, 16(1): 119-147.

Report of Jamab Consulting Engineers Company (2011). Upgrading Studies for Integrated Water resources Planning and Management of Iran., pp. 420. (In Persian)
Safavi, HR; Enteshari, S (2016). Conjunctive use of surface and ground water resources using the ant system optimization. Agricultural Water Management, 173: 23-34.

Shafer, J; Labadie, J (1978). Synthesis and Calibration of a River Basin Water Management Model. Completion Report No. 89, Colorado Water Resources Research Institute, Colorado State University, Fort Collins CO.

Shourian, M; Mousavi, SJ; Menhaj, MB; Jabbari, E (2008). Neural-network-based simulationoptimization model for water allocation planning at basin scale. Journal of Hydroinformatics, 10(4): 331-343.

Sprague, R; Carlson, E (1982). Building Effective Decision Support Systems", Prentice-Hall, Inc., Englewood Cliffs, N.J. pp.329.

Zaman, AM; ahman, SMM ; Khan, MR (2009). Development of a DSS for Integrated Water Resources Management in Bangladesh. $18^{\text {th }}$ World IMACS / MODSIM Congress, Cairns, Australia 13-17 July 2009, pp.1-7. 